\title{
Development of Particle Distribution Estimation (PDE) Model Based on Particulate Mass Concentration for Indoor Ambient Air Monitoring
}

\author{
Angelo Sean Francis ${ }^{1}$, Fuei Pien Chee ${ }^{1 *}$, Justin Sentian² and Jackson Hian Wui Chang \\ ${ }^{1}$ Faculty science and Natural Resources, Universiti Malaysia Sabah, \\ Jalan UMS, 88400 Kota Kinabalu, Sabah, Malaysia. \\ ${ }^{2}$ Climate Change Research Group (CCRG), Faculty science and Natural Resources, \\ Universiti Malaysia Sabah, Jalan UMS, 88400 Kota Kinabalu, Sabah, Malaysia. \\ ${ }^{3}$ Preparatory Center for Science and Technology, Universiti Malaysia Sabah, \\ Jalan UMS, 88400 Kota Kinabalu, Sabah, Malaysia
}

\begin{abstract}
Particulate Matter (PM) mass concentration is one of the key elements in determining Air Quality Index (AQI). Conventionally, PM mass concentration is measured using Federal Reference Method (FRM) which apply the filter based gravimetric method. While the mass concentration may be used as a threshold limit on particulate matter exposure, recent studies had shown that particles distribution may provide better insight on the adverse effect of particulate matter exposure. In this study a Particle Distribution Estimation Model (PDE) was developed for determination of particle distribution based on particulate mass concentration. The model was developed using correlation between Particle distribution and particulate mass concentration from purple Air-II (PA-II) an optical based research grade instrument. The Particle Distribution Estimation (PDE) Model was evaluated at an outdoor environment. The estimated particle distribution from the PDE shows excellent correlation with the actual particle distribution from the reference instrument with R2is higher than o.8.
\end{abstract}

Keywords: PM2.5; Particle Distribution; Particulate Matter; Air Quality

\section{INTRODUCTION}

Particulate Matter (PM) mass concentration is one of the key indicators in determining Air Quality Index (AQI) (Brunekreef \& Holgate, 2002; Lee, 2010). Various epidemiological studies have reported the health threat proposed by PM to our cardiovascular system (Chuang et. al., 2011; World Health Organization, 2014). Regulatory bodies such as the US Environmental Protection Agency (EPA), has set a certain threshold limit for particulate matter exposure based on mass concentration (Esworthy, 2015).
Conventionally, the PM mass concentration was monitored through the gravimetric method which is also known as the Federal Reference Method (FRM) (Hall et. al., 2014). Though being known to provide high accuracy on PM mass concentration, the gravimetric method has always hindered deeper understanding on health threat of PM especially to those who are exposed in vicinity. The high cost of deployment and long sampling interval (Chow \& Chow, 2012; Schmidt-Ott \& Ristovski, 2006) of the gravimetric method has made it unfavourable for large monitoring network hence limiting better understanding on spatial and temporal PM concentrations.

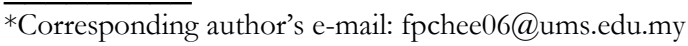


While the PM mass concentration may be good indicator for PM exposure, recent studies also reported that the particles distribution may provide better insight on particulate matter exposure (Weijers et. al., 2004). The severity of particulate matter exposure is measured based on its penetration rate into our respiratory tract which is classified based on their aerodynamics diameter (Brown et al., 2013). The smaller the particle size the more deeply it will penetrate the respiratory tract causing more adverse effect. Therefore, it is important to consider the particle distribution in determining PM exposure.

In this study, a Particle Distribution Estimation Model (PDE) was developed for determination of particle count distribution based on particulate mass concentration. The model was developed by correlating the reported particle distribution with the reported PM mass concentration from the purpleAir-II (PA-II).

\section{RESEARCH METHODOLOGY}

\section{A. Reference Instrument Description}

PA-II is a research grade instrument that had been evaluated and compared with two FEM instruments namely the MetOne Beta Attenuation Method (BAM) which is certified FEM for PM 2.5 and PM 10.0 and the GRIMM which is certified FEM for PM2.5 in both laboratory and field evaluation (Pa-ii, Pm, Pm, Ii, \& An, n.d.). The evaluation summary between PA-II against the FEM instrument is as shown in Table 1.

Table 1: Evaluation Summary between PA-II and FEM instrument

\begin{tabular}{|c|c|c|c|c|}
\hline \multirow{2}{*}{ Instrument } & \multirow{2}{*}{$\begin{array}{c}\text { Evaluation } \\
\text { Period }\end{array}$} & \multicolumn{3}{|c|}{$\mathbf{R}^{2}$} \\
\cline { 3 - 5 } & & PM & PM & PM \\
& & $\mathbf{1 . 0}$ & $\mathbf{2 . 5}$ & $\mathbf{1 0 . 0}$ \\
\hline \multirow{2}{*}{ FEM } & 1 Hour & & $\mathbf{0 . 9 2}$ & $\mathbf{0 . 6 4}$ \\
\cline { 2 - 5 } & 24 Hour & & $\mathbf{0 . 9 7}$ & $\mathbf{0 . 7 4}$ \\
\hline \multirow{2}{*}{ PA II } & 1 Minute & 0.98 & $\mathbf{0 . 9 7}$ & 0.70 \\
\cline { 2 - 5 } & 1 Hour & 0.98 & $\mathbf{0 . 9 8}$ & 0.72 \\
\cline { 2 - 5 } & 24 Hour & 0.99 & $\mathbf{0 . 9 8}$ & 0.78 \\
\hline
\end{tabular}

The PA-II operates based on laser scattering employing the PMS5003 particulate matter sensor from Plan tower for its detection. The PA-II is capable of reporting particle distribution and mass concentrations simultaneously and it also comes with data logger that save data approximately every 1-minute interval.

\section{B. Reference Instrument Reported Particle Distribution}

In this study, we have classified the particle distribution channel into five smaller range as shown in Table 2. The particle size ranges were then used to determine each of the mean particle diameter in each respective channel. This mean diameter will be used to obtain the volume of particle for derivation of the Particulate Distribution Estimation (PDE) Linear Model.

Table 2: Particle Size Range

\begin{tabular}{|c|c|c|c|}
\hline Channel & Range & $\begin{array}{c}\text { Particle } \\
\text { Size } \\
\text { Range, } \\
\mu \mathrm{m}\end{array}$ & $\begin{array}{c}\text { Mean } \\
\text { Diameter, } \\
\mu \mathrm{m}\end{array}$ \\
\hline A & $\begin{array}{l}0.3 \mu \mathrm{m} \\
>x \geq 0.5 \\
\mu \mathrm{m}\end{array}$ & $0.4,0.5$ & 0.45 \\
\hline B & $\begin{array}{l}0.5 \mu \mathrm{m} \\
>x \geq 1.0 \\
\mu \mathrm{m}\end{array}$ & $\begin{array}{l}0.6,0.7, \\
0.8,0.9,1.0\end{array}$ & 0.80 \\
\hline $\mathrm{C}$ & $\begin{array}{l}1.0 \mu \mathrm{m} \\
>x \geq 2.5 \\
\mu \mathrm{m}\end{array}$ & $\begin{array}{l}1.1,1.2,1.3 \\
1.4,1.5, \ldots \\
2.5\end{array}$ & 1.80 \\
\hline $\mathrm{D}$ & $\begin{array}{l}2.5 \mu \mathrm{m} \\
>x \geq 5.0 \\
\mu \mathrm{m}\end{array}$ & $\begin{array}{l}2.6,2.7 \\
2.8,2.9, \\
3.0, \ldots, 5.0\end{array}$ & 3.80 \\
\hline $\mathrm{E}$ & $\begin{array}{l}5.0 \mu \mathrm{m} \\
>x \geq \\
10.0 \mu \mathrm{m}\end{array}$ & $\begin{array}{l}5 \cdot 1,5 \cdot 2,5 \cdot 3, \\
5 \cdot 4,5 \cdot 5, \ldots, \\
10.0\end{array}$ & $7 \cdot 55$ \\
\hline
\end{tabular}




\section{Reference Instrument Reported Mass} Concentration

The PA-II report mass concentration in three bin channels namely PM 1.0, PM 2.5 and PM 10.0 in the unit of $\mu \mathrm{g} / \mathrm{m}^{3}$. This mass concentration is represented using two algorithms which can be classified as Standard Atmosphere Algorithm (AT) and Industrial Algorithm (CF). The AT algorithm represents the pollutants commonly found in an indoor environment whereas the $\mathrm{CF}$ algorithm reports reading based on industrial metal particle densities and is suitable for environments such as an industrial production workshop (Tan, 2017). Since this experiment is conducted in an indoor environment, the mass concentration reported using AT algorithm was selected in this study.

\section{Site Description}

This study was set up in an indoor environment. The site selected was Material science lab which is located in the Faculty of Science and Natural Resources, University Malaysia Sabah (N 6॰1'54.2094”, E 117'11.316”) for a period of seven days from $10^{\text {th }}$ March 2018 until $17^{\text {th }}$ March 2018. The PA-II was placed approximately $1.5 \mathrm{~m}$ from the ground and could continuously sample the ambient air without any stimulation. The source of the sampled air throughout the sampling period mostly come from the natural ventilation of the lab which resourced from either the exchange of air during door opening or air from the air conditioner.

Meteorological conditions during the evaluation period were normally distributed. The lowest temperature, relative humidity and pressure recorded during this study were 26.7 $\mathrm{C}, 40 \% \mathrm{RH}$ and $1006 \mathrm{~Pa}$ respectively, while the highest temperature, relative humidity and pressure were $33.8{ }^{\circ} \mathrm{C}, 57$ \%RH and 1012 pa respectively. Hourly PM 1.0 mass concentrations varied from 1.44 to $21.78 \mu \mathrm{g} / \mathrm{m}^{3}, \mathrm{PM} 2.5$ from 2.47to $32.21 \mu \mathrm{g} / \mathrm{m}^{3}$ and PM 10.0 from 2.69 to $32.82 \mu \mathrm{g} / \mathrm{m}^{3}$.

\section{RESULTS AND FINDING}

\section{A. Derivation of Particulate Distribution Estimation (PDE) Linear Model}

Optical instrument does not directly measure the mass concentration of PM, the mass concentration is calculated based on particle size distribution under assumptions that all particles is spherical and density is known (Liu et. al., 2017). The derivation of particle count to mass concentration is given by(Friedlander, 2000);

mass concentration, $\mathrm{Kg} / \mathrm{m}^{3}=\rho \int \frac{\pi d_{p^{3}}}{6} \cdot N\left(d_{p}\right)(1)$

Where $\rho$ is the density function,$\frac{\pi d_{p^{3}}}{6}$ is the particle size volume in respect to the mean diameter, $\boldsymbol{d}_{\boldsymbol{p}}$ (Refer to Table 3 ) and $\boldsymbol{N}\left(\boldsymbol{d}_{\boldsymbol{p}}\right)$ is the total number of particle in the particle bin channel. In this study, the PDE model was derived based on the inversion of equation (1) such that the total number of particles is equal to

$$
\int N\left(d_{p}\right)=\frac{\text { mass concentration, } \mathrm{kg} / \mathrm{m}^{3}}{p \times\left(\pi d_{p^{3}} / 6\right)}(\mathbf{2})
$$

In this study, we identified the PM 1.o to be contributed by summation of particle in channel A and B whereas the PM 2.5 is contributed by particle in channel $A$ to $C$ and the PM 10.0 is contributed by particle in channel A to E. Table 3shows the summary of each contributing particle distribution channel and their confidence interval in respect to the mass concentration as well as the contributing density function for each mass concentration which were obtained by dividing each mass concentration channel with the summation of the total volume from each of the contributing particle distribution bin. Figure 1 shows the density function plot.

Table 3: Summary of contributing particle distribution channel to mass concentration

\begin{tabular}{|c|c|c|c|c|c|c|c|c|c|}
\hline & \multirow{2}{*}{$\begin{array}{c}\text { Contributing } \\
\text { Channel }\end{array}$} & \multirow{2}{*}{$\mathbf{R}^{2}$} & \multicolumn{5}{|c|}{ Confidence Interval, CI } & \multicolumn{2}{|c|}{ Density Function, $\mathrm{kg} / \mathrm{m}^{3}$} \\
\hline & & & $\mathbf{A}$ & $\mathbf{B}$ & $\mathbf{C}$ & $\mathbf{D}$ & $\mathbf{E}$ & Pmed & $\rho_{Q 1}$ \\
\hline PM 1.0 & $A+B$ & 0.99 & $35 \%$ & $65 \%$ & $\mathrm{X}$ & $\mathrm{X}$ & $\mathrm{X}$ & $4.91 \times 10^{16}$ & $4.39 \times 10^{16}$ \\
\hline PM 2.5 & $\mathrm{~A}+\mathrm{B}+\mathrm{c}$ & 0.99 & $16 \%$ & $31 \%$ & $53 \%$ & $\mathrm{X}$ & $\mathrm{X}$ & $3.27 \times 10^{16}$ & $3.03 \times 10^{16}$ \\
\hline
\end{tabular}




\begin{tabular}{|c|c|c|c|c|c|c|c|c|c|}
\hline PM 10.0 & $\begin{array}{c}\mathrm{A}+\mathrm{B}+\mathrm{C}+\mathrm{D} \\
+\mathrm{E}\end{array}$ & 0.99 & $11 \%$ & $20 \%$ & $33 \%$ & $16 \%$ & $20 \%$ & $2.19 \times 10^{16}$ & $1.76 \times 10^{16}$ \\
\hline
\end{tabular}
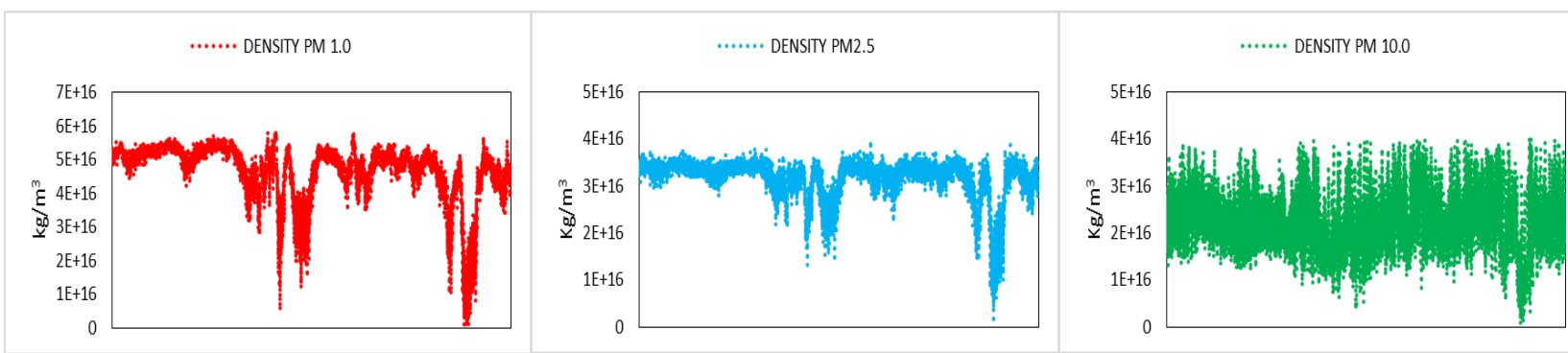

Figure 1: Density function plot for PM 1.0, PM 2.5 and PM 10.0

Based on the density function in table 3 , it was observed that the density function varies for each particulate mass conversion. This is most likely due to particle composition (Wang et. al., 2015). Therefore, it is crucial to identify which density function should be applied. Using the confidence interval from each channel in table 3 , the density function for each of the respective particle distribution channel can be determined. If the $\mathrm{CI}$ is less than 50\%, the First quartile

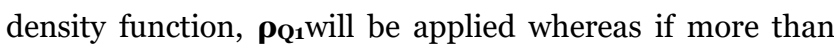

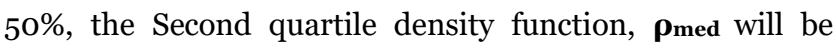
applied.

Therefore, by using equation (2) and each of the of the designated density function for each channel in respect to the mass concentration in Table 3 , the estimated particle distribution from each respective channel can then be derived such that from the PM 10.0 mass concentration the particle distribution is given by;

$$
\text { Particle Count } A=\frac{P M 10}{\left(1.76 \times 10^{16} \mathrm{Kg} / \mathrm{m}^{3}\right)\left(\boldsymbol{\pi} \boldsymbol{d}_{p A^{3}} / \mathbf{6}\right)} \times
$$

(3)

Particle Count $B=\frac{P M 10}{\left(1.76 \times 10^{16} \mathrm{Kg} / \mathrm{m}^{3}\right)\left(\boldsymbol{\pi} \boldsymbol{d}_{\boldsymbol{p} A^{3}} / \mathbf{6}\right)} \times$ $0.20(C I) \quad$ (4)

Particle Count $C=\frac{P M 10}{\left(1.76 \times 10^{16} \mathrm{Kg} / \mathrm{m}^{3}\right)\left(\pi \boldsymbol{d}_{\boldsymbol{p A}} \mathbf{A}^{3 / 6}\right)} \times$ $0.33(C I) \quad$ (5)

Particle Count $D=\frac{P M 10}{\left(1.76 \times 10^{16} \mathrm{Kg} / \mathrm{m}^{3}\right)\left(\boldsymbol{\pi d} \boldsymbol{p A}^{3} / \mathbf{6}\right)} \times$ $0.16(C I) \quad$ (6)

$$
\begin{gathered}
\text { Particle Count } E=\frac{P M 10}{\left(1.76 \times 10^{16} \mathrm{Kg} / \mathrm{m}^{3}\right)\left(\pi d_{p A^{3}} / 6\right)} \times \\
0.20(C I) \quad \text { (7) }
\end{gathered}
$$

\section{B. Validation of the Particulate Distribution Estimation (PDE) Linear Model}

To evaluate the developed model, the experiment setup was replicated in a new environment in an outdoor environment at Kg. Marakau, Ranau, Sabah (N $5^{\circ} 57^{\prime}$ 28.8”, $\left.\mathrm{E} 116^{\circ} 41^{\prime} 13.2^{\prime \prime}\right)$ for a period of seven days from $19^{\text {th }}$ April 2018 until $26^{\text {th }}$ April 2018 side by side with our developed particulate matter measurement device (Chee et. al., 2018).The Meteorological conditions in the new site during the evaluation period were normally distributed.

The lowest temperature, relative humidity and pressure recorded during this study were $30.55^{\circ} \mathrm{C}, 67.26 \% \mathrm{RH}$ and $1010 \mathrm{~Pa}$ respectively, while the highest temperature, relative humidity and pressure were $32.7^{\circ} \mathrm{C}, 72 \% \mathrm{RH}$ and $1013 \mathrm{~Pa}$ respectively. Hourly PM 1.0 mass concentrations varied from 17 to $158 \mu \mathrm{g} / \mathrm{m}^{3}$, PM 2.5 from 52 to $255 \mu \mathrm{g} / \mathrm{m}^{3}$ and PM 10.0 from 57 to $283 \mu \mathrm{g} / \mathrm{m}^{3}$.

The mass concentration and particle count from the new site were monitored through the PA-II instrument and the data were applied to the PDE model to obtain the estimated particle distribution. The estimated particle count was then correlated with the actual particle count from the PA-II and the regression plot is as shown in Figure 2.

Both estimated and actual particle count in this study were represented in the unit of particles/o.1 L. 


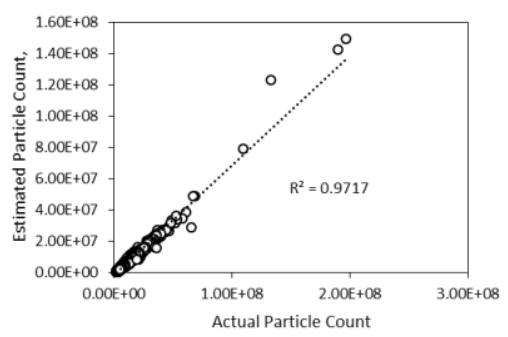

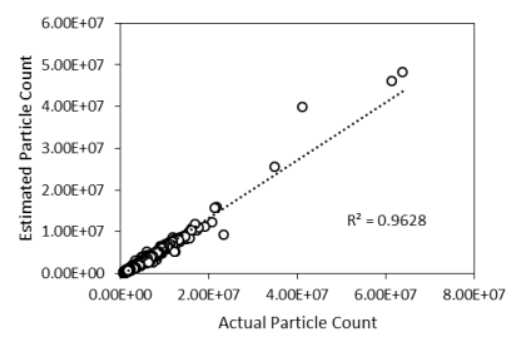

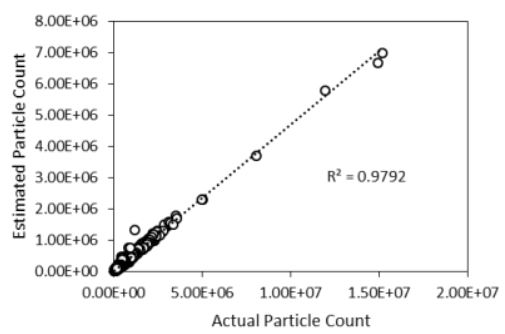

E

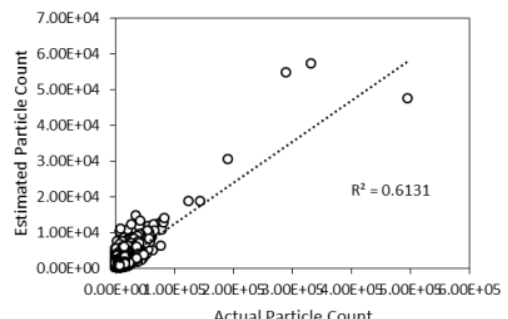

Actual Particle Count

Figure 2: Regression plot between estimated particle distributions against actual particle distribution measured from PA-II

Based on the regression plot, it is observed that the estimated particle distribution agree well with the actual particle distribution with $\mathrm{R}^{2}$ is more than 0.8 for particle distribution channel A to D and $\mathrm{R}^{2}>0.6$ for channel E. This justifies the reliability of the developed PDE model for measuring particle distribution.

\section{CONCLUSION}

APDE model for estimation of particle distribution based on particulate mass concentration was developed in this study. This model was evaluated in a new environment and based on the findings; it was observed that the estimated particle distribution shows excellent correlations with the actual particle distribution from the reference instrument. The estimated Particle count distribution between $0.3 \mu \mathrm{m}$ to 2.50 m (Channel A to D) shows strong positive correlation with the reference data with $\mathrm{R}^{2}>0.8$ whereas moderate correlations were observed for estimated Particle count distribution between $5.0 \mu \mathrm{m}$ to $10.0 \mu \mathrm{m}$ (Channel E) with $\mathrm{R}^{2}>$ o.6.

\section{ACKNOWLEDGEMENT}

The authors acknowledge the financial support from Universiti Malaysia Sabah on Bantuan Penyelidikan Pascasiswazah (GUG0204-1/2018), Skim Penyelidikan Bidang Keutamaan (SBK 0352-2017) and Skim Geran Inovasi (SGI 0054- 2018). 


\section{REFERENCES}

Brown, J. S., Gordon, T., Price, O., \& Asgharian, B. 2013, Thoracic and respirable particle definitions for human health risk assessment, 1-12.

Brunekreef, B., \& Holgate, S. T. 2002, Air pollution and health. Lancet, 36o(9341), 1233-1242.

Chee, F. P., Angelo, S. F., Kiu, S. L., Justin, S., \& Jackson, C. H. W. 2018, real time particulate matter concentration measurement using laser scattering, 13(22), 8873-8879.

Chow, J. C., \& Chow, J. C. 2012, Measurement Methods to Determine Compliance with Ambient Air Quality Standards for Suspended Particles Measurement Methods to Determine Compliance with Ambient Air Quality Standards for Suspended Particles. Journal of the Air \& Waste Management Association, 2247(320-382).

Chuang, K.-J., Yan, Y.-H., Chiu, S.-Y., \& Cheng, T.-J. 2011, Long-term air pollution exposure and risk factors for cardiovascular diseases among the elderly in Taiwan. Occupational and Environmental Medicine, 68(1), 64-68.

Esworthy, R. 2015, Air Quality : EPA's 2013 Changes to the Particulate Matter (PM) Standard. Retrieved from

http://www.fas.org/sgp/crs/misc/R42934.pdf

Friedlander, S. K. 2000, Smoke, dust, and haze (Second Edi). New York: Oxford University Press.

Hall, E. S., Kaushik, S. M., Vanderpool, R. W., Duvall, R. M., Beaver, M. R., Long, R. W., \& Solomon, P. A. 2014, Federal Reference Method (FRM), Federal Equivalent Method (FEM), National Ambient Air Quality Standards (NAAQS), Sensors; Federal Reference Method (FRM), Federal Equivalent Method (FEM), National Ambient Air Quality Standards (NAAQS), Sensors. American Journal of
Environmental Engineering, 4(6), 147-154.

Lee, S. W. 2010, Fine particulate matter measurement and international standardization for air quality and emissions from stationary sources. Fuel, 89(4), 874-882.

Liu, D., Zhang, Q., Jiang, J., \& Chen, D. R. 2017 , Performance calibration of low-cost and portable particular matter (PM) sensors. Journal of Aerosol Science, 112(May), 1-10.

Pa-ii, P., Pm, F., Pm, F., Ii, P.-, \& An, M. (n.d.). Manufacturer / Model : From the laboratory studies , temperature and relative. Retrieved October 13, 2018, from http://www.aqmd.gov/docs/defaultsource/aq-spec/summary/purpleair-pa-ii--summary-report.pdf?sfvrsn $=10$

Schmidt-Ott, A., \& Ristovski, Z. D. 2006, Measurement of airborne particles. Indoor Environment: Airborne Particles and Settled Dust, 56-81.

Tan, B. K. 2017, Laboratory Evaluation of Low to Medium Cost Particle Sensors by.

Wang, Y., Li, J., Jing, H., Zhang, Q., Jiang, J., Biswas, P., ... Biswas, P. 2015, Laboratory Evaluation and Calibration of Three Low-Cost Particle Sensors for Particulate Matter Measurement Laboratory Evaluation and Calibration of Three Low-Cost Particle Sensors for Particulate Matter Measurement, 6826(January 2018).

Weijers, E. P., Khlystov, A. Y., Kos, G. P. A., \& Erisman, J. W. 2004, Variability of particulate matter concentrations along roads and motorways determined by a moving measurement unit, 38 , 2993-3002.

World Health Organization. 2014, Public Health, Enviromental and Social Dertiminants of Health (PHE), (63). 